\title{
EM BUSCA DE CATEGORIAS TEÓRICAS- METODOLÓGICAS PARA ANALISAR A ARTE POR UMA PERSPECTIVA QUEER
}

\section{IN SEARCH OF THEORETICAL AND METHODOLOGICAL CATEGORIES TO ANALYZE ART THROUGH A QUEER PERSPECTIVE}

Eduardo Pereira Francisco ${ }^{1}$

\begin{abstract}
RESUMO
A ideia de "artivismo" surge como conceito que procura compreender um tipo de fenômeno contemporâneo que habita a intersecção de arte e política numa perspectiva ativista. Mais do que estabelecer um limite entre as duas definições, pretende-se entender a complexidade da relação entre os dois campos. Acredita-se que esse conceito auxilie na compreensão de como algumas manifestações artísticas estão alinhadas aos ativismos das dissidências sexuais e de gênero. Estudar os pontos de contato existentes entre arte e ativismo político, principalmente no campo das sexualidades e gêneros, permite pensar estratégias que podem ser mobilizadas como ação de mudança social no combate às violências da heteronormatividade sobre corpos e subjetividades que nela não se encaixam e, também, refletir sobre o potencial da arte na criação de novas subjetividades que fogem às normas de gênero e sexualidade. Assim, o objetivo deste artigo é revisar e sistematizar algumas apropriações teóricometodológicas realizadas por pesquisadoras e pesquisadores do campo das artes e dos estudos queer que: 1) definem "artivismo" e buscam pensar categorias metodológicas para analisar o fenômeno que ele delimita; 2) analisam produções artísticas através de uma perspectiva queer; 3 ) permitem pensar como essas manifestações se alinham a um ativismo das dissidências sexuais e de gênero. Como resultado deste exercício de sistematização, esquematiza-se um quadro de indicações metodológicas como sugestão de roteiro de pesquisa. Mais do que um manual rígido de análise, ele deve servir como um roteiro aberto que permita a inclusão de novas operações e apropriação de novos conceitos e categorias a depender da demanda da pesquisa.
\end{abstract}

Palavras-chave: Arte. Ativismo. Artivismo. Queer. Sexualidade. Gênero.

1 Mestre pelo Programa de Pós-Graduação em Comunicação e Cultura Contemporâneas na linha de pesquisa de Análise de Linguagens e Produtos da Cultura Mediática da Universidade Federal da Bahia (POSCOM/UFBA). Graduado em Comunicação Social com habilitação em Jornalismo pela Faculdade Social da Bahia. Integra o Grupo de Pesquisa em Cultura e Sexualidade (CUS) e o Grupo de Pesquisa em Gênero, Tecnologias Digitais e Cultura (GIG@), ambos vinculados à Universidade Federal da Bahia. Salvador (BA). Brasil. E-mail: eduardo.p.francisco@gmail.com. 


\section{ABSTRACT}

The idea of "artivism" emerges as a concept that seeks to understand a kind of contemporary phenomenon that inhabits the intersection of art and politics in ativist perspective. Rather than establishing a boundary between the two definitions, it aims to understand the complexity of the relationship between the two fields. It is believed that this concept assist to understand how some artistic manifestations are aligned with the activism of sexual and gender dissidence. Study the existing contact points between art and political activism, especially in the sexualities and genders field, allows to think strategies that can be deployed as an action of social change in the fight against heteronormativity's violence on bodies and subjectivities that did not fit and, also, reflect on the potential of art in the creation of new subjectivities that flee to gender and sexuality norms. The objective of this article is to review and systematize some theoretical and methodological appropriations made by the arts and queer studies' authors wich: 1) define "artivism" and seek to think methodological categories to analyze the phenomenon that it delimits; 2) analyze artistic productions through a queer perspective; 3) allow us to think how this phenomenon align to sexual and gender dissidence's activism. As a result of this exercise, it is proposed a frame of methodological indications as search script suggestion. More than an analysis' manual, it should serve as an open roadmap for the inclusion of new operations and the appropriations of new concepts and categories depending on the demand of the object.

Keywords: Art. Artivism. Ativism. Queer. Sexuality. Gender. 


\section{Introdução}

O principal interesse neste artigo é a intersecção entre produções artísticas e os ativismos das dissidências sexuais e de gênero. Como as linguagens artísticas dialogam com uma perspectiva queer das sexualidades e do gênero? Como elas são capazes de causar rupturas nas normas e fomentar outras subjetividades? Como essas produções "artivistas" vêm sendo realizadas? Como pensar a intersecção arte e política em toda sua complexidade? É possível fazer uma genealogia dessas manifestações?

Essas são algumas das inquietações iniciais e mais gerais que encaminham esse trabalho. Infelizmente, seu caráter preliminar ainda não permite respondê-las. Porém, esboça-se aqui um ponto de partida. Assim, o objetivo é revisar e sistematizar algumas apropriações teóricas e metodológicas que vêm sendo empreendidas por autoras e autores das artes e dos estudos queer na tentativa de compreender o fenômeno dos "artivismos" e suas relações com o campo das sexualidades e do gênero.

Especificamente, interessa compreender como o termo "artivismo" é conceituado e mobilizado enquanto categoria analítica. Que tipo de manifestações artísticas ele compreende? O exercício de sistematização aqui empreendido também procura investigar como essas pessoas estão analisando obras de arte que dialogam com as diferenças sexuais e de gênero a partir de uma perspectiva queer, assim como essas próprias produções reconfiguram as concepções sobre o tema e apresentam potencial de produzir novas subjetividades, que causam rupturas com a heteronormatividade.

Desse modo, esse texto se divide em três partes. A primeira se dedica a discutir algumas definições de "artivismo". A segunda apresenta algumas abordagens analíticas que se propuseram pensar produções artísticas a partir do queer. Por fim, realiza-se uma sistematização dos principais conceitos e categorias abordados anteriormente em forma de indicações metodológicas que podem ser seguidas e aprimoradas em pesquisas futuras.

Este trabalho se situa no contexto da atual pesquisa coordenada pelo professor Leandro Colling "Outras políticas para o respeito às diferenças sexuais e de gênero no Brasil hoje”, no Grupo de Pesquisa 
em Cultura e Sexualidades (CUS) da Universidade Federal da Bahia. Especificamente, o empreendimento realizado neste artigo resulta da literatura acessada e amplamente discutida em grupo ao longo do componente curricular Cultura, Gênero e Sexualidade, ministrado pelos professores Leandro Colling e Djalma Thürler no primeiro semestre letivo de 2016 no Programa Multidisciplinar de Pós-Graduação em Cultura e Sociedade, que teve como eixo temático os artivismos das dissidências sexuais e de gênero.

\section{A ideia de artivismo}

A conceituação mais sintética e completa sobre a ideia de artivismo é aquela trazida por Paulo Raposo (2015), que inclusive é citada por Colling (2016):

Artivismo é um neologismo conceptual ainda de instável consensualidade quer no campo das ciências sociais, quer no campo das artes. Apela a ligações, tão clássicas como prolixas e polémicas entre arte e política, e estimula os destinos potenciais da arte enquanto ato de resistência e subversão. Pode ser encontrado em intervenções sociais e políticas, produzidas por pessoas ou coletivos, através de estratégias poéticas e performativas [...]. A sua natureza estética e simbólica amplifica, sensibiliza, reflete e interroga temas e situações num dado contexto histórico e social, visando a mudança ou a resistência. Artivismo consolida-se assim como causa e reivindicação social e simultaneamente como ruptura artística - nomeadamente, pela proposição de cenários, paisagens e ecologias alternativas de fruição, de participação e de criação artística (RAPOSO, 2015, p. 5).

Essa definição dada por Raposo (2015) é pertinente porque contempla o fenômeno em suas várias dimensões. Ela expõe a controvérsia do conceito no meio acadêmico; leva em conta as potencialidades artísticas e políticas do artivismo; localiza o realizador da ação enquanto indivíduo ou coletivo, assim como as linguagens que são mobilizadas em sua realização. Ou seja, o conceito delimita teoricamente o fenômeno, mas não o torna fechado.

Essa posição é muito similar a tomada por Julia Giovanni (2015, p. 1415). Em sua revisão teórica, a autora chama a atenção para o fato de que 
artivismo não se configura nem como arte nem como política. $\mathrm{O}$ "termo artivismo propõe um foco de análise dirigido às sobreposições e intersecções entre experiência política e experiência estética." Tal consideração realizada pela autora é importante porque é necessário encarar o artivismo como algo "novo". Não no sentido de localização temporal, enquanto algo que nunca tenha acontecido, mas como nunca antes delimitado teoricamente. Isso implica em pensar novas ferramentas analíticas que possam se apropriar tanto de conceitos advindos da estética e das artes quanto dos estudos sobre políticas sem, no entanto, se prender às normas conceituais definidas por esses campos.

Isso fica claro, por exemplo, quando Rui Mourão (2015) explica o funcionamento do circuito de produção das artes e problematiza o modo como o artivismo pode não se inserir neste sistema:

O sistema da arte, apesar das suas especificidades, inserese rizomaticamente no mesmo macrossistema histórico da sociedade de onde resulta. A organização social cria condições favoráveis para que a arte possa acontecer, simultaneamente estrutura uma série de dinâmicas, legitimações, hierarquias e relações de poder que instrumentalizam a arte de acordo com os interesses dos agentes dominantes nesse mesmo sistema. Agentes que por sua vez estão geralmente dependentes de uma série de outras relações de poder e interesses económicos, financeiros, políticos e sociais. A prática artística surge, portanto, enquadrada por premissas paradoxais e dificilmente tem condições de concretização ou legitimação pública sem estar inserida no sistema da arte. Porém, inserida nesse sistema dificilmente escapa a um certo fechamento à sociedade como um todo pelas inerentes dinâmicas elitistas, capitalistas e individualistas. Nesse sentido o artista deve ser original e competitivo visto o sucesso ser acessível a poucos - apesar de enquanto produtor ser frequentemente quem menos ganha materialmente na cadeia transacional (MOURÃO, 2015, p. 56).

O que não exclui o fato de que essas pessoas possam estar submetidas a essas pressões, apesar de ser difícil dizer que artivistas necessariamente são artistas, já que, como apontam Giovanni (2015) e Salvador Vidal- 
Ortiz, Marva Viteri \& José Amaya (2014), pessoas sem formação ou profissão artística podem também ser artivistas. No entanto, quando fazem parte do campo das artes, elas podem ser empurradas pelas próprias forças do campo (no sentido bourdieusiano ${ }^{2}$ ) para essa arte fronteiriça.

Assim, há sempre uma posição dual do artivismo em que alguns conceitos e considerações das áreas específicas da política ou das artes podem ser úteis para se pensar o fenômeno. Porém, há uma investigação que parece ser muito importante, visto que a literatura aqui discutida a realiza: a análise das condições sociais, culturais e históricas de emergência desses artivismos. E não no sentido de origem, conforme explica Colling (2016, p. 77), mas através da apropriação metodológica da genealogia de Michel Foucault. Em seu texto, Colling chama a atenção para o sentido de emergência e proveniência de que se está falando. Assim, proveniência deve ser entendida como as marcas no corpo imprimidas pela história, enquanto a emergência representa as condições sociais de florescimento do fenômeno, o conflito e o jogo de forças.

De certo modo, os trabalhos revisados realizam esse exercício nas formas de artivismos que eles se preocupam em pensar. Giovanni (2015), por exemplo, diz:

[...] A relação entre as formas de ação coletiva e a possibilidade de transformação das relações de poder se recoloca como problema vivo, [...].

Neste cenário, a emergência do termo artivismo, como categoria analítica, marca um interesse, político e teórico, em formas de ação coletiva cujo efeito e possíveis interpretações não se esgotam na taxonomia da provável orientação ideológica dos participantes, nem na possível funcionalidade que possam cumprir nos jogos políticoeleitorais e midiáticos das democracias representativas, cuja explicação não termina na identificação dos fatores contextuais, históricos ou socioeconômicos que fomentaram sua erupção. Por um lado, trata-se de formas histórica e simbolicamente associadas ao ativismo, ao protesto, a irrupção de processos coletivos de autoorganização, denúncia e reivindicação de direitos,

2 Pierre Bourdieu realiza uma pertinente análise sobre o funcionamento do campo da arte na obra "As Regras da Arte". Apesar de não o problematizarmos aqui, certamente sua abordagem oferece muitas contribuiçõoes. 
acirrados em momentos de crise econômica e social, que mesmo quando relativamente autônomos em relação às estruturas organizativas e instituições precedentes (partidos, sindicatos, movimentos setoriais), mobilizam recursos e repertórios próprios do campo de relações que nos acostumamos a chamar de 'política'. Ao mesmo tempo, trata-se de experiências coletivas mal contidas pelas fronteiras convencionais da política em sentido estrito, formas de dissenso e reivindicação que mais se aproximam à dimensão cotidiana dos "modos de vida" e "contraculturas" do que das estruturas programáticas e ideológicas que o senso comum atribui aos movimentos sociais. Ao mesmo tempo em que habitam o universo da ação e da organização política, trata-se de modos de intervenção notavelmente ligados a práticas experimentais próprias dos mundos da arte ou, em muitos casos, explicita ou implicitamente informadas pela história do deslizamento de práticas artísticas para fora do campo de autonomia que define a arte moderna, ao encontro de outras dimensões da vida social [...] (GIOVANNI, 2015, p. 14).

Neste trecho, Giovanni (2015) opta por fazer uma análise mais estrutural e macro. Ao mesmo tempo que explica as condições de emergência dos artivismos, ela o delimita em suas dimensões de fronteira com o que se considera arte e política. Colling (2016) também realiza esse exercício, mas numa perspectiva mais micro. Ele se preocupa com as questões dos ativismos LGBT institucionalizados comparados aos considerados queer, que possuem uma orientação mais artivista. Assim, o autor tanto discute marcas que estabelecem diferenças entre os dois movimentos, quanto tenta explicar as condições de emergência dos artivismos queer no Brasil:

[...] o que temos percebido com mais intensidade nos últimos anos é a emergência de outros coletivos e artistas que trabalham dentro de uma perspectiva das dissidências sexuais e de gênero e que, ao mesmo tempo, explicitam suas intenções políticas, ou melhor, que criam e entendem as suas manifestações artísticas como formas distintas de fazer política, em especial quando contrapostas às formas mais "tradicionais" usadas pelo movimento LGBT e feminista mainstream.

Ao analisar o trabalho de algumas artivistas, Lessa (2015) já aponta para algumas diferenças entre essas produções. Uso intenso de novas tecnologias e redes sociais, produções não voltadas para espaços fechados ou museus, mas para as ruas, festas e outros espaços públicos de sociabilidade facilmente acessados, horizontalidade das 
produções e, fundamentalmente: "as artivistas, por meio dessas práticas, questionam o corpo, o sexo, e o modelo dessexualizado do contrato de casamento, propondo novas formas mais criativas de estar no mundo e de sentir a multiplicidade e o valor da liberdade para a vida" [...] (COLLING, 2016, p. 81).

Deste modo, é possível perceber um segundo movimento analítico nos textos dessas pesquisadoras e pesquisadores. Em um primeiro momento há um debate mais amplo sobre artivismo; em seguida, um aprofundamento, um exercício de vislumbre de manifestações específicas que podem ser consideradas artivismos.

Se em Colling (2016) e Vidal-Ortiz, Viteri \& Amaya (2014) essa discussão surge através dos movimentos das dissidências sexuais e de gênero, no caso de Giovanni (2015) essa atenção se volta para os movimentos de ocupação motivados pelas crises econômica e política dos países em que aconteceram. Um posicionamento que todas(os) ${ }^{3}$ apresentam em comum é a postura de saber localizado (HARAWAY, 1995). As autoras e autores enxergam seus interesses de pesquisas e campos empíricos como lugar de produção de saberes. Assim, há um exercício de escuta, em que mais do que partir com pressuposições teóricas e com uma metodologia a serem aplicadas, há uma produção dialógica. Ou seja, o desenvolvimento teórico sobre o conceito de artivismo passa a ser realizado a partir da observação e descrição do fenômeno. Claro que há um suporte bibliográfico que apoiam as pesquisadoras e pesquisadores em suas proposições. No entanto, no que diz respeito à ideia central, não há um quadro teórico já estabelecido até pela novidade do conceito. Ressalta-se, no entanto, que isso é diferente, por exemplo, de se apropriar de referências da estética e da política em busca de ferramentais analíticos que possam ajudar na compreensão da linguagem dessas manifestações - que é mais uma necessidade para o avanço das análises. Uma passagem de Giovanni (2015) ilustra bem essa ida a campo mais com perguntas do que hipóteses e caminhos claros a serem seguidos:

Em que reside a potência política e o caráter "criativo" de uma ação social? Dependem de seus resultados ou

3 Evita-se utilizar o " $x$ " aqui como rasura da desinência de gênero porque tal uso dificulta a leitura de alguns softwares de audiodescrição para pessoas com deficiência visual ou baixa visão. 
impactos externos, de seus fins, de seus meios, ou quem sabe da natureza dos sujeitos que a levam a cabo? Trata-se, como a magia e o mana, de noções nativas de eficácia? Dependem de certas características intrínsecas dessas ações ou de convenções institucionais, tal como a beleza e a autoridade atribuídas às obras de arte? Ainda que não ofereçam respostas, essas mesmas sensações e percepções com relação à potência de reverberação política ou estética da ação coletiva não podem ser negligenciadas: são talvez algumas das pistas mais importantes de que dispomos para investigar o papel dos movimentos sociais nos processos de transformação social. (GIOVANNI, 2015, p. 16)

Apesar de Giovanni (2015) centralizar muito de sua atenção aos movimentos coletivos, o que ela diz não exclui inferências sobre o fenômeno artivista em suas diferentes formas de manifestação. Assim, seguindo esse rastro dos pesquisadores, a primeira noção pertinente para uma proposta de análise dos artivismos é a caracterização dessas manifestações.

Parece muito difícil que haja uma delimitação fechada acerca do conceito - e isso nem é algo a que se busca nem parece uma necessidade para seu estudo. Uma operação que surge em todos os textos aqui discutidos sobre o assunto é essa preocupação em caracterizar o fenômeno.

A sugestão é que mais importante do que perguntar se uma manifestação é ou não artivista, seria questionar se ela apresenta marcas que podem ser consideradas artivistas e que marcas são essas. Certamente, tais marcas não podem ser caracterizadas sem um contexto. Exemplos são bem claros nas produções de Giovanni (2015) e Vidal-Ortiz, Viteri \& Amaya (2014). Em ambos os textos, os momentos que mais nos ajudam a compreender o que se configura como artivismo são aqueles em que os autores e autoras se preocupam em caracterizar os movimentos que analisam. É interessante notar o modo como Giovanni (2015) traça características que considera gerais para o artivismo a partir de sua experiência com os movimentos de ocupação. Apesar da crítica cabível por ela não levar em conta, no contexto de seu artigo, outras possíveis formas de artivismo (que não sejam nem em forma de ocupação, nem coletivas, por exemplo), isso não exclui o fato de que seu exercício analítico em uma primeira instância registra, de fato, um tipo específico de artivismo, e em segunda, permite que o mesmo caminho percorrido 
por ela possa ser apropriado para se pensar manifestações artivistas de outras naturezas.

Atitude similar acontece com Vidal-Ortiz, Viteri \& Amaya (2014) que em seus trabalhos procuram compreender o fenômeno em sua intersecção com as dissidências sexuais e de gênero. Porém, diferente de Giovanni (2015), os autores e a autora conseguem alcançar uma síntese que caracteriza os artivismos para além da especificidade dos movimentos que observa - inclusive, destacam - esse transbordamento dos limites das preocupações-alvo desses movimentos se torna uma característica importante. Por exemplo, a síntese que Vidal-Ortiz, Viteri \& Amaya (2014, p. 191) fazem como caracterização dos artivismos latino-americanos é bastante útil para pensar o fenômeno de um modo geral:

[...] apesar de dialogarem com os ativismos hegemônicos, não seguem suas tendências dominantes e denunciam aquilo que tais tendências escondem ou tentam impedir de emergir [...]; Algumas dessas práticas privilegiam estratégias de ação e intervenção que favorecem o emotivo, o afetivo ou o expressivo, mas não se reduzem a isso (...); Em seus processos de exploração e criação, essas práticas preferem alianças e ações particulares e com grupos específicos em vez de conglomerados massificados ou padronizados [...]; As formas de organização que privilegiam coletivos, oficinas, escolas de formação, implicam em serem apresentadas como práticas culturais e acima de tudo como forma de experimentação grupal, não em apresentar resultados da realização de uma agenda programada, como seria típico de outras formas de organização mais estruturadas para a eficiência. (...) $\mathrm{O}$ interesse por privilegiar vozes marginalizadas, as histórias "menores" ou "sem importância" torna relevante o particular, o específico e não o geral ou o macro, que é favorecido em outras propostas de transformação e ativismo normalizantes (VIDAL-ORTIZ, VITERI \& AMAYA, 2014, p. 191, tradução nossa). ${ }^{4}$

4 “[...] Si bien comparten espacios o dialogan con activismos hegemónicos, no siguen sus tendencias dominantes y denuncian aquello que tales tendencias esconden, silencian o impiden emerger [...]; Algunas de estas prácticas privilegian estrategias de acción e intervención que favorecen lo emotivo, lo afectivo o lo expresivo, pero no se reducen a ello [...]; En sus procesos de exploración y creación, estas prácticas prefieren alianzas y acciones particulares y con grupos específicos, en lugar de ubicaciones generales en conglomerados masificados o definidos de manera estándar [...]; El que se 
Outro traço metodológico trazido por pesquisadoras e pesquisadores é o método genealógico de Foucault conforme sugere Colling (2016), como já foi relatado na introdução. Como explica o autor, tal exercício consiste em identificar a proveniência e a emergência desse fenômeno. Tal percurso metodológico leva em conta a especificidade das manifestações artivistas, pensando desde o indivíduo que a produz, até sua linguagem, contexto sócio-cultural e político, entre outros questionamentos, como os realizados por Giovanni (2015) na citação mais acima.

Colling (2016, p. 83-85) realiza um esforço inicial ao tentar descrever essa emergência dos artivismos queer no Brasil contemporâneo: o aumento do conservadorismo, apesar da conquista de alguns direitos; movimento LGBT hegemônico muito atrelado ainda às políticas identitárias de forma essencialista, o que favorece sua assimilação à heteronormatividade; crescimento dos estudos sobre sexualidade e gênero, especialmente os estudos queer e das dissidências sexuais e de gênero; ampliação do acesso e popularização das mídias sociais; ampliação da exposição de temáticas LGBT nos meios de comunicação de massa; crescimento da visibilidade de pessoas que reivindicam identidades mais flexíveis e que transbordam as definições normativas.

privilegien formas de organización como lo colectivo, el taller, la escuela de formación, implica que aquello presentado como producto de su práctica cultural es por sobre todo una forma de experimentación grupal, no el resultado de llevar a cabo una agenda programada, como sería propio de otras formas de organización estructuradas para la eficiencia. [...] El interés por privilegiar las voces marginalizadas, los relatos "menores" o las historias "sin importancia" hace relevante lo particular, lo específico y no lo general o lo macro, que es favorecido en otras porpuestas de transformación y activismo normalizantes." 


\section{Categorias e trajetórias de pesquisa para se analisar a arte a partir de uma perspectiva queer}

\subsection{Pesquisas na literatura}

É perceptível dois movimentos metodológicos a partir da revisão bibliográfica das autoras e autores que analisaram obras literárias: 1) uma discussão prévia da vida do escritor ou escritora, assim como o contexto da sociedade em que essas pessoas viviam; 2) a análise de uma ou mais de suas obras, estabelecendo-se pontes entre sua produção literária e suas biografias.

O primeiro aspecto é mais identificável nas análises de Renata Teixeira (2007) e Helder Maia (2014) e menos em Anselmo Alós (2012) e Adriana Azevedo (2016). Já o segundo movimento é adotado por todas(os), apesar de que em Alós (2012) e Azevedo (2016) não aparecem como foco de atenção detalhada a relação entre vida do escritor(a) e obra. Não que eles ignorem a subjetividade e dissidências dos criadores(as), mas sim que elas são tomadas como pressupostas e, talvez por isso, não são analisadas.

Em Alós (2012), outra possibilidade para essa lacuna na análise, talvez seja o formato do trabalho - diferente de outros textos aqui debatidos, se trata de um artigo e não de uma tese ou dissertação ${ }^{5}$. Esse primeiro movimento, por exemplo, é o que permite Teixeira (2007) pensar no conceito de Escrita Transformista, a partir de Copi, e Maia (2014) no conceito de Escritura Queer através Perlongher e também do próprio Copi. Assim, o trajeto metodológico adotado por Teixeira (2007) e Maia (2014) os capacitam a produzir conceitos a partir do tensionamento das proposições teóricas queer com o que não só as obras analisadas "dizem", mas também a partir da biografia desses autores.

O segundo movimento, de análise das obras, contempla três passos: resumo das obras estudadas, citando trechos pertinentes para o que se propõe analisar; apropriação teórica de conceitos analíticos (seja da literatura, da filosofia, ou dos estudos queer); comentário analítico e

5 Aproveita-se para reforçar que o critério de seleção das obras revisadas foi a bibliografia do componente curricular Cultura, Gênero e Sexualidade, como já explicado na introdução. 
proposições resultantes do processo de análise. O conceito de escrita transformista é pensado por Teixeira (2007) a partir da própria escrita de Copi. Ela se dá fortemente marcada pela ficcionalização de si e pela estética camp. Nestes dois trechos o conceito é bem delimitado e caracterizado na obra da autora:

$\mathrm{Na}$ sua escrita, está a capacidade de não perder sua mobilidade de retorno e nem as multiplicidades, ou seja, uma escrita transformista: que remete ao gay, ao homo, à "loca", mas também ao feminino, ao machão latinoamericano [...], ao tango e sua linguagem corporal, ao espanhol estilizado dos folhetins dos anos 30 e 40 [...], à língua das ratas (escrita ao contrário, como num espelho invertido, por Gouri, em La Cité des rats), ao uso do francês língua estrangeira do exilado argentinoparisiense...

$[\ldots]$

Situações, portanto, como o exílio parisiense (e a assimilação do francês como língua de expressão e criação literária) e as tematizações constantes e recorrentes da morte, da desmemória (e tantas outras que já mencionamos) são representações recorrentes em Copi e sinais do seu universo.

Afinal, num exemplo mais extremo, antes de morrer na vida há sempre a possibilidade de continuar atuando, representando; ou seja, a própria ficcionalização de si é um procedimento da escrita transformista de Copi. Se a arte é tal simulacro, representação, reflexo, ao converter a morte em mera idéia, Copi a torna tão mortal quanto ele próprio e podem seguir sucedendo novas mortes ficcionais a novas ressurreições: o teatro da vida no teatro, mundo dentro de outro mundo, barroco (TEIXEIRA, 2007, p. 200-202).

Porém, deve se reforçar a ressalva de que, apesar de Teixeira procurar diferenciar a arte transformista da identidade travesti, isso não se dá de forma muito clara no texto, o que gera alguns problemas em relação a sua proposição. Tal confusão se faz evidente, por exemplo, no seguinte trecho:

Nada mais teatral que a travesti, se nos damos conta de que o teatro é um 'espelho ilusório', mas em paralelo algo tão real como irreal (pois reproduz a vida, porém sem ser a vida). A travesti é uma imagem refratária: construída pelo artifício, pela máscara, com maquiagem, adereços postiços e atuando como aquilo que não é (mas sem deixar de sê-lo) (TEIXEIRA, 2007, p. 194). 
A posição aqui é de que ela se refere à arte transformista e não necessariamente à identidade travesti. Teixeira (2007) também parte do conceito de camp, conforme discutido por Susan Sontag (1987), para caracterizar o que chama de escrita transformista. Para ela, a estética barroca de Copi, que inclui realidades dentro de outras, assim como os recursos de "nonsense" e comédia colaboram nessa construção da escrita copiana: "a potência da máscara, exagerada; do disfarce; mas também da conversibilidade, do câmbio, das indistinções da androginia" (TEIXEIRA, 2007, p. 196).

Explorar as linhas da fronteira, os traços femininos da virilidade masculina; certa masculinidade nas mulheres mais femininas; a androginia e, ao extremo, o hermafroditismo; as possibilidades de mudar de sexo incontáveis e infindas vezes: eis o que faz Copi em seu "baile de Loucas". E esse caminho se faz sempre ancorado no riso (TEIXEIRA, 2007, p. 197).

Vale lembrar que Teixeira (2007) discute uma noção também trazida por Maia (2014, p. 62): língua/literatura menor, com base em Gilles Deleuze e Félix Guattari (1978). Ela faz referência a produção pensada em espanhol e escrita em francês por Copi, durante seu exílio, assim como à produção de Perlongher "através do portunhol e [...] de um processo de lumpenização, que implica um embarrocamento da língua".

A ideia de língua menor, no entanto, se encontra mais aprofundada no texto de Maia (2014, p. 59-61). Conforme ele explica com base em Deleuze, ela implica na construção de uma língua construída por uma minoria dentro da língua maior de forma a desterritorializá-la.

[...] De forma resumida, as três características das literaturas menores seriam: a desterritorialização da língua, a ligação do individual com o imediato político e o agenciamento coletivo de enunciação. Menor, portanto, não seria um adjetivo que qualificaria determinadas literaturas, mas as condições revolucionárias de qualquer literatura no seio daquela que se chama maior ou estabelecida.

Dessa forma, a desterritorialização da linguagem nas literaturas menores presupõe: estar estrangeiro em sua própria língua [...]; abrir o léxico a intensidades interiores inéditas [...] ou inaudíveis; além de servir-se da sintaxe como um grito [...], um retorno do reprimido. As literaturas menores são, portanto, uma literatura política das minorias [...], uma língua tomada num devir minoritário [...], que 
recusa a inscrição da literatura nas formas dominantes da linguagem [...] (MAIA, 2014, p. 60).

Outro conceito relevante invocado por Maia (2014) é o de escritura. Ele faz esse percurso na busca de definir uma escritura queer. Para iniciar sua discussão, ele parte de Roland Barthes. Maia diz, assim, que a escritura está mais relacionada a uma amarra entre o escritor e a sociedade que habita, que a uma escola, gênero ou cânone literário. A escritura se dá através da singularidade histórica, reafirma ele com base em Barthes. Os "[...] escritores, mesmo que separados pela língua, por acidentes de estilo, pelo tempo ou pelo espaço geográfico, são capazes de compartilhar uma mesma escritura, ou seja, de estabelecer textualmente relações afetivas e políticas" (MAIA, 2014, p. 13).

Assim, Maia (2014) irá percorrer um trajeto de descrição do que ele chama de escritura queer e tecer essa ideia conjuntamente às análises de Copi e Perlongher. Em sua caracterização da escritura queer, três aspectos são notados: a desterritorialização da heteronorma; a multiplicidade de devires; a defesa de uma escritura da diferença em contraposição à igualdade e à tolerância.

As escrituras queer seriam, portanto, perturbadoras da normalidade, dos territórios hegemônicos e da heteronormatividade, logo, elas não se colocam como discursos de tolerância, mas como discursos de afirmação da diferença, escrituras que desterritorializando normas e convenções culturais permitam a transformação tanto da cultura como do leitor. Uma escritura, portanto, que não apela a normalidade, que não pede para ser tolerada, que não quer ser vista como parte da diversidade humana, que é passível de engendrar uma política da diferença e que aspira a um diálogo solidário e transformador da sociedade e do leitor (MAIA, 2014, p. 27).

Mudando para outro autor com outra perspectiva de análise, especificamente da narratologia, Alós (2012) defende que a recusa do binarismo na obra "Onde andará Dulce Veiga?", de Caio F. Abreu, se dá como investimento político de desestabilizar a heteronorma mais do que uma negação do personagem protagonista em assumir sua sexualidade. Isso se dá por um reconhecimento do personagem a partir da valorização das práticas sexuais, mais do que se restringir às identidades sexuais. 
Uma noção fundamental apropriada pelo autor para analisar a narrativa é a de focalizador/ focalização. Segundo Alós (2012), a noção de focalização e a identificação desta posição com o narrador-protagonista permitem analisar as percepções do personagem e identificar as transformações sofridas por ele ao longo da narrativa.

[...] o que se quer afirmar é que, mesmo que a identidade da voz narrativa permaneça a mesma ao longo do romance, dado ser todo ele conduzido pelo jornalista anônimo, algo muda no decorrer dos eventos de forma a sinalizar as transformações da percepção desse narrador. A questão da percepção é fundamental, para que se possa realizar a distinção entre quem narra, quem focaliza e quem é objeto da focalização $[\ldots]$.

Em Onde andará Dulce Veiga?, a focalização é predominantemente interna. Isso não ocorre apenas porque a articulação narrativa se dá a partir de um narradorprotagonista, mas sim porque há uma coincidência entre a percepção do narrador e a percepção do personagem central. Identificar o focalizador como interno ou externo, em si, não diz muita coisa à investigação do romance; importa ressaltar quais os valores que estão sendo articulados por ele (ALÓS, 2012, p. 179).

O autor indica alguns trechos - como quando ele relata a relação com Pedro, um antigo amor - em que é possível apreender o focalizador no romance. A compreensão de Alós (2012, p. 180) é de que a "reprovação à manutenção de estereótipos sexuais fortemente associados à homossexualidade é um elemento textual que permite postular que a percepção deste está além das limitações impostas pela mentalidade hétero".

Já Azevedo (2016) não detém sua análise apenas na literatura, mas em obras de diversas linguagens. O que ela toma como fio condutor é a discussão em torno dos conceitos de lar, casa e família. Aqui, no entanto, procurou-se se manter ao debate realizado no primeiro capítulo de sua tese, dedicado à obra literária de Silviano Santiago, "Stella Manhattan". A autora começa seu argumento identificando o modo como a casa faz parte do dispositivo de sexualidade enquanto um espaço "normativo e de controle, funcionando como um dispositivo importante na produção subjetiva e sexual dos filhos da família que a habita" (AZEVEDO, 2016, p. 18). Assim, ela toma a experiência do personagem protagonista da obra analisada, Eduardo, que se torna "uma espécie de estrangeiro na residência da família" tão logo tem sua homossexualidade descoberta. 
Azevedo (2016) discute, então, o modo como as pessoas que possuem dissidências sexuais e de gênero se tornam um "corpo estranho" no ambiente familiar e sofrem a violência psicológica da rejeição, que culmina com a expulsão da casa dos pais ou com a própria fuga da pessoa por não mais se sentir parte daquele espaço.

Deste modo, ao identificar essa experiência como uma vivência comum entre essas pessoas, Azevedo (2016, p. 26) recorre à noção de arquivo de sentimentos, com base em Ann Cvetkovich (2003), para "mapear como as populações queer ressignificam a ideia de trauma".

Ann Cvetkovich, em seu livro The Archive of Feelings: Trauma, Sexuality and Lesbian Public Cultures (2003), elabora uma reflexão sobre as conexões entre o trauma relacionado à sexualidade e os eventos históricos mundiais. Segundo Cvetkovich, o impacto do trauma sexual não é experimentado coletivamente, como o de grandes eventos históricos, da guerra ou do genocídio, talvez por ser confinado às esferas doméstica e privada. Sua reflexão está mais interessada em lésbicas que passaram por traumas relacionados a abuso sexual e depressão, mas também faz uma relação desse tipo de trauma com a crise da AIDS, que ofereceu uma clara evidência de que algumas vidas são mais importantes que outras. Para burlar o modo como a crise da AIDS era vivenciada somente na esfera doméstica, ativistas e familiares de vítimas criaram diversos tipos de ação pública. Cvetkovich traz o relato de David Wojnarowicz, que sugere que levassem o corpo de "amigos, vizinhos, amantes e estranhos" que falecessem em decorrência da AIDS para a frente da Casa Branca, em Washington, para que a dimensão da tragédia fosse marcada no tempo, no espaço e na história de forma pública (...) (AZEVEDO, 2016, p. 20).

Assim, como explica a autora acima, tipos de ações queer que tentam "abrir" esse arquivo de sentimentos para o público, de forma a atingir a sociedade e impactar as subjetividades em função de transformar o modo como esses traumas são encarados, implica em ações políticas queer. Tais ações objetivam marcar o trauma vivido numa comunidade marginalizada "no tempo, no espaço e na história de forma pública". É, por exemplo, o caso do Memorial dos Homossexuais Perseguidos pelo Nazismo que a própria autora visitou em viagem a Berlim.

Em continuidade à sua análise desse fenômeno da rejeição de jovens LGBT do ambiente familiar, a autora vai se perguntar sobre as vivências 
contemporâneas dessas pessoas. Como um dos aspectos mais preocupantes, ela vai apontar que a família é também "uma fonte de suporte financeiro e segurança, já que é cada vez mais difícil e demorado entrar no mercado de trabalho e conseguir ter autonomia financeira na transição da juventude para a vida adulta" (AZEVEDO, 2016, p. 25). Sendo assim, o momento de saída do armário se torna ainda mais temido por essas pessoas visto que ao serem rejeitados por suas famílias isso também implicará na perda de "suas estruturas espacial e financeira além de afetiva".

Em sua análise da obra de Silviano Santiago, "Stella Manhattan", o personagem Eduardo, conforme Azevedo explica, não perde a estrutura financeira já que ele ganha um emprego nos Estados Unidos, porém ele perde suas estruturas afetivas e familiares não só pela expulsão de casa, mas também pelo afastamento geográfico.

Os queers, que passaram pela patologização da sua própria vivência, tendem a negar esse status de patologia de sua experiência traumática. Cvtkovich nos traz o pensamento de Eve Sedgwick para explorar como a autora faz um link entre emoção e sexualidade, e como a categoria da vergonha (shame) sugere que "as experiências traumáticas de rejeição e humilhação [vividas pelas minorias sexuais] estão conectadas com a formação de identidades que são mais do que formações reativas." Essas experiências, por parte dessas populações, abarcam uma série de afetos, incluindo não somente o luto e a perda, mas também "a raiva, a vergonha, o humor, a sentimentalidade e mais" (CVETCKOVICH, 2003, p. 47-48)

O trauma doméstico queer, portanto, pode ser observado por outro viés, abrindo as experiências históricas e sociais em termos afetivos, como afirma Cvetkovich. "A abordagem queer do trauma pode apreciar formas criativas através das quais as pessoas respondem a isso". Como consequência da experiência traumática de Eduardo/Stella podemos perceber a construção de uma nova forma de domesticidade queer, e de uma forma de conceber um lar, através de outras relações afetivas, para além da família que o rejeitou (AZEVEDO, 2016, p. 26).

É seguindo essa proposta de domesticidade queer, que Azevedo (2016, p. 31) segue sua análise identificando o modo como ela "se baseia em uma falha na lógica patriarcal e capitalista do sucesso e da reprodução". Isso vai se dar por exemplo a partir do modo como essa domesticidade 
queer gera novas formas de "afetividade, acolhimento, convívio", parentalidades e assunção de papéis familiares antes vistos como apenas representáveis através da forma de família tradicional. Mais a frente, Azevedo (2016, p. 38) convoca "pensar o queer no sentido de desaprender, desaprender modos de vida, categorias".

\subsection{Pesquisas nas artes plásticas, visuais e de performance}

Rosa Blanca (2016) realiza uma revisão crítica da história da arte a partir do fio condutor da performance. A proposta dela é demonstrar como linguagens como o teatro, a pintura e a literatura, através da performance, produziam subjetividades e identidades artísticas capazes de borrar as fronteiras nos binarismos de gênero.

Outro exercício analítico da autora é questionar como essas práticas de arte performance flertam com a política ativista na contemporaneidade, que objetivam justamente acabar com as violências relacionadas às sexualidades e gêneros dissidentes. Assim, ela reconhece essa performance como arte conflito. Porém, a maior contribuição, sem dúvida, é o caráter provocativo de seu texto que leva a questionar o próprio estatuto da arte na história. Sua interpretação da performance é de que a prática é uma arte que não é "arte" no sentido tradicional e desestabiliza a própria categoria ao penetrar as outras linguagens artísticas.

O fato da autora utilizar como exemplo os rituais e as pinturas produzidas pelos povos pré-colombianos, como os maias, enquanto performances, faz questionar que concepção contemporaneamente se tem de arte e por que ela exclui algumas expressões culturais desse âmbito. $\mathrm{O}$ que regula se algo é arte ou não? Há um jeito decolonial ${ }^{6}$ de se pensar a arte? Seria o caso de se pesquisar outras noções de arte,

6 Nota da edição: Por sua vez, a expressão "decolonial" não pode ser confundida com "descolonização". Em termos históricos e temporais, esta última indica uma superação do colonialismo; por seu turno, a ideia de decolonialidade indica exatamente o contrário e procura transcender a colonialidade, a face obscura da modernidade, que permanece operando ainda nos dias de hoje em um padrão mundial de poder. Trata-se de uma elaboração cunhada pelo grupo Modernidade/Colonialidade nos anos 2000 e que pretende inserir a América Latina de uma forma mais radical e posicionada no debate pós-colonial, muitas vezes criticado por um excesso de culturalismo e mesmo eurocentrismo devido à influência pós-estrutural e pós-moderna.” 
considerando suas finalidades, interpretações e contextos numa época pré-colonização, por exemplo? Ou até práticas artísticas decoloniais? Essas são algumas das questões que o artigo de Rosa Blanca (2016) suscita.

Tiago Sant'Ana (2016) propõe uma metodologia peba, queer. Para ele há, na historiografia do queer, uma valorização maior das produções do norte global enquanto as dos países do sul ficam relegadas ao esquecimento. No Brasil, isso é bastante evidente de outro modo: a historiografia do queer no país fica restrita às regiões Sul e Sudeste. As criações das outras regiões, principalmente do norte e nordeste, são invisibilizadas e não citadas nesses trabalhos ${ }^{7}$.

Assim, ele se fundamenta na discussão dos saberes subalternos sobre a produção de conhecimento e dos estudos queer. A partir de uma metodologia que se inspira na etnografia e da análise fílmica, ele analisa um recorte biográfico de Jomard Muniz de Britto e de seus filmes. O maior ponto de tensionamento no trabalho de Sant'Ana é sua escrita, bem jornalística, que intercala descrições e entrevistas com Jomard e as análises de suas obras, desde uma perspectiva queer e decolonial. Através de sua análise, procura evidenciar como a produção do artista era capaz de produzir subjetividades outras que não estivessem vinculadas às normatividades heterossexistas e coloniais sobre os corpos.

Adriano Cysneiros (2014) recorre a metodologia da cartografia como percurso. Conforme explicou ${ }^{8}$, a cartografia, baseada nas indicações de Suely Rolnik (2006), seria uma anti-metodologia porque choca com alguns pressupostos do meio acadêmico. Diferente dos trajetos de pesquisa mais tradicionais, a cartografia é uma metodologia aberta onde a pesquisadora ou pesquisador deixa suas crenças, concepções de mundo e conhecimentos na soleira da porta antes de adentrar no campo de estudo. Esses saberes anteriores só devem ser resgatados na saída, onde a volta será acompanhada de uma revisão crítica desses

7 Algumas dessas inquietações foram expostas pelo próprio Tiago Sant'Ana ao participar de um dos encontros do componente curricular Cultura, Gênero e Sexualidade, com a finalidade de apresentar o processo de produção de sua dissertação e discuti-la com a turma.

8 Adriano Cysneiros também participou de um dos encontros com a turma, da mesma forma que Sant'Ana. 
conhecimentos com base no contato que se teve com o "objeto de pesquisa"9.

Mais do que partir de hipóteses ou da aplicação de uma teoria ou método sobre o "objeto", se trata de um exercício de escuta. Assim, o processo de construção da pesquisa não surge de cima para baixo, ou da academia para o "objeto", mas sim o contrário. O alvo de interesse se torna o ponto de partida. É a partir do contato com ele que o pesquisador ou pesquisadora vai estruturar suas questões, hipóteses e revisará seu referencial teórico-metodológico.

Tanto Matheus Santos (2013) quanto Cíntia Braga (2015) acionam o conceito de performatividade de gênero, elaborado por Judith Butler ${ }^{10}$. Claro, utilizam também conceitos específicos das artes que pretendem analisar - a estética abjeta, no caso de Santos (2013), e a estética cinematográfica, em Braga (2015). Em Santos (2013), o conceito de performatividade é apropriado pelo autor para analisar a performance de Adrian Piper e Robert Mapplethorpe. Em Braga (2015), é utilizado na análise fílmica de "Bombadeiras".

Nos dois trabalhos, há preocupação em ressalvar as diferenças entre os conceitos de arte performance e performatividade. A proposição é de que as(os) artistas (e as pessoas retratadas ou representadas em suas obras), ao realizarem sua arte, estão incorporando e reiterando gestos, ações e discursos que se assimilam à norma ou rompem com ela, ou até mesmo no ato de assimilação provocam ruptura (como no caso das travestis e mulheres trans, que na busca de um ideal de gênero geram novas vivências do feminino, como retratado em "Bombadeiras").

De qualquer modo, tanto Braga (2015) quanto Santos (2013) se apropriam do conceito de performatividade como categoria de análise. O que permite Santos (2013), por exemplo, realizar essa leitura do trabalho de Adrian Piper:

9 As aspas visam problematizar a hierarquização tradicional entre pesquisador e objeto. Este artigo se alinha a uma perspectiva feminista que questiona a dinâmica naturalizada entre essas duas instâncias.

10 Para mais detalhes sobre a noção de performatividade ver "Problemas de Gênero Feminismo e subversão da identidade" (BUTLER, 2013, p. 194-195). 
Piper, como o ser mítico, andava pelas ruas da cidade frequentando praças, estabelecimentos comerciais e aberturas de exposições em galerias de arte. Sempre buscando comportar-se como um "homem de verdade", a artista esforçava-se por imitar os gestos tidos como masculinos: o sentar com as pernas abertas (proibido desde muito cedo às meninas que devem "se preservar"), o andar impositivo, com o peitoral projetado para frente (como fazem os homens para exaltar a sua força e "impor respeito") e mesmo o "jeito masculino" de fumar um cigarro (que jamais deve ser delicado como o modo das damas).

A artista construía para si um corpo masculino a partir da repetição de determinadas ações e, através da reiterada citação destes atos, evidenciava a relação entre gênero e performatividade [...] (SANTOS, 2013, p. 89).

Apesar de serem pertinentes essas apropriações do conceito de performatividade de gênero, não há a realização de muitos tensionamentos ou proposições teóricas novas. Diferente do exercício de Cysneiros (2014), que se apropria de alguns conceitos e teoriza sobre eles ao mesmo tempo que realiza sua análise.

Apesar de abordar variados conceitos dos estudos queer, considera-se que as ideias centrais na obra de Cysneiros (2014) são: Família, Fracasso, Estética da negatividade e Culpa, vergonha e humilhação. O conceito de Fracasso, segundo Cysneiros (2014), remete a uma proposição de Jack Halberstam (2012). Para ele, a incoerência no eixo sexo-gênero-desejo-práticas sexuais implica em um fracasso para a heteronorma.

O exercício analítico realizado por Cysneiros (2014) consiste justamente em tensionar como o grupo Dzi Croquettes subverte a lógica do fracasso - o que implica numa dualidade do conceito de fracasso. Uma coisa é o fracassar da arte, enquanto realização artística que não sai como planejada ou que não alcança os objetivos do artista, outra é o fracasso diante da norma, que não necessariamente carrega a negatividade da outra instância e pode ser subvertido.

[...] Se aos sujeitos que tem comprometida a coerência entre sexo-gênero-desejo-prática sexual é atribuído o status de fracassados por haverem falhado em levar a cabo o projeto heterossexual que a cultura lhes impõe, os Dzi vêm mostrar que tal fracasso pode ser extremamente divertido e prazenteiro. A frustração do fracasso em copiar a matriz de 
gênero pode ser ressignificada no prazer em jogar, em desafiar a norma, em resistir e criar novas possibildiades de subjetivação.

$[\ldots]$

Outras tantas possibilidades desse gozo são apontadas por Halberstam (2011). Segundo ele, o fracasso nada mais é que a recusa do sucesso, sendo o sucesso a busca da confirmação do já conhecido; o que nos exige um comprometimento com a repetição, a tradição, o método, a disciplina e a norma. O sucesso está intimamente relacionado às ideias de progresso, permanência e lucro; um conceito cujo movimento é dificultado em razão da trama da lógica moderna que o enreda. $\mathrm{O}$ fracasso, por consequência, é o não lugar discursivamente construído para abrigar e conter aqueles que foram discursivamente constituídos como ininteligíveis por seus desejos - e/ou corpos - orientarem-se ao novo, ao irrepetível, ao irreprodutível e/ou àquilo que não é rentável ou lucrativo, o que não trará retorno objetivo e mensurável (HALBERSTAM, apud, CYSNEIROS, 2014, p. 77-78).

Cysneiros (2014) se apropria do conceito de família ao analisar as relações existentes entre os integrantes do Dzi Croquettes. Apesar de os artistas se designarem conforme os padrões da instituição familiar tradicional, classificando um como mãe, outro como pai, por exemplo, o autor ressalva que a potência está justamente no modo como eles estabelecem uma nova corrente de afetos: "A família Dzi era uma família de mulheres - a mãe, as filhas, as tias, as sobrinhas - com apenas um homem, o pai. Nessa família, nem a homossexualidade nem o incesto eram tabus" (CYSNEIROS, 2014, p. 78).

Como diz o autor, os Dzi alteram o conteúdo, mas não abandonam a forma. Numa situação em que muitos foram exilados de suas famílias, há uma subversão. Modificam-se conteúdo e relações que estruturam essa família: "amizade, afeição, atração sexual, intelectual, artística". Porém, o autor não deixa de trazer ressalvas apontadas por Halberstam e Judith Butler:

A paródia da família feita pelos Dzi Croquettes faz surgir e ser questionada a dinâmica do parentesco. Para que serve o parentesco? Para que servia ele lá e então, por meio do documentário, para que serve ele aqui e agora? A quem serve o parentesco? O parentesco é redutível à família? Que questões políticas estão encerradas nessa dinâmica? Qual o papel do sexo e da sexualidade no parentesco?

$[\ldots]$ 
Ao compor uma família de pessoas não heterossexuais, a estrutura do parentesco como inerentemente vinculada ao casamento é desafiada. Como efeito colateral, desmonta-se também a ideia que une o parentesco à conjugalidade heterossexual monogâmica e ao sexo (CYSNEIROS, 2014, p. 80-81).

A essas ideias, Cysneiros (2014) também discute a estética da negatividade e as noções de culpa, vergonha e humilhação. Através dessa rede conceitual, que inclui as duas outras categorias trazidas antes, ele analisa o documentário sobre os Dzi Croquettes. O que ele reconhece como uma estética da negatividade é o fato de esses artistas perceberem como a cultura marca seus corpos negativamente e não se preocuparem em recusar essas marcações.

Eles "não buscam positivar suas vidas, forjar um estilo de vida hegemônico, mais aceitável [...]. Também não se vitimizam, justificam, nem desculpam. Eles assumem em público aquilo que, no privado, já envergonha a maioria das pessoas" (CYSNEIROS, 2014, p. 82).

Sobre a culpa, vergonha e humilhação, o autor diz:

Apesar das emoções de culpa, vergonha e humilhação serem tratadas aqui em conjunto, é importante diferenciálas: "culpa é acreditar que se fez algo mau, vergonha é acreditar que se é algo mau, e humilhação é ver-se tratado como mau injustamente" (SLUZKI, 2011, p. 81). Esses sentimentos se dão frente a uma situação ou" antecipação de uma situação pública de descoberta ou desmascaramento, em suma, da exposição de algo que somos ou atos que cometemos ou omitimos; no caso da vergonha, o nosso olhar coincide com o do outro, no caso da humilhação, não.

$[\ldots]$

Já a humilhação se caracteriza como uma "experiência de ataque à dignidade, ao orgulho ou ao poder" (SLUZKI, 2011, p. 82, grifos do autor). No mundo subjetivamente constituído para os envergonhados e humilhados pelas experiências sociais recorrentes de vergonha $\mathrm{e}$ humilhação, as regras imobilizam bem como roubam a voz e a capacidade dos sujeitos de avaliar a si e ao seu contexto com base em alternativas e recursos (SLUZKI, apud, CYSNEIROS, 2014, p. 84). 


\section{Sistematização e indicações metodológicas}

É interessante notar como os conceitos e movimentos metodológicos são complementares, mesmo quando foram mobilizados para se analisar diferentes linguagens artísticas. Com exceção de alguns poucos conceitos, como focalização (ALÓS, 2012) e língua/literatura menor (TEIXEIRA, 2007; MAIA, 2014), todos são passíveis de serem apropriados para analisar produções artísticas independente de sua linguagem.

Retomando o que foi discutido na primeira parte, três operações metodológicas marcantes foram identificadas: a caracterização dessas manifestações artísticas; a identificação de marcas que possam ser consideradas artivistas; a análise genealógica, buscando demarcar a proveniência e a emergência do fenômeno artivista.

Na segunda parte, discutiu-se apropriações de categorias teóricometodológicas de análise pelos autores e autoras revisados na literatura e nas artes plásticas, visuais e de performance. Procurou-se sistematizar conceitos úteis para uma análise literária desde uma perspectiva queer. Foram abordadas noções como as de escrita transformista (TEIXEIRA, 2007), língua/literatura menor (TEIXEIRA, 2007; MAIA, 2014), focalização (ALÓS, 2012), escritura queer (MAIA, 2014) e arquivo de sentimentos queer (AZEVEDO, 2016).

Sugere-se uma proposta de uso complementar dessas categorias para

análise literária e, com o devido trabalho de revisão dessas noções, até outras formas de linguagens. Isso, inclusive, é sugerido por Maia (2014) com relação à escritura queer, visto que ele destaca em seu texto essa possibilidade. O mesmo se dá com Azevedo (2016) no que diz respeito ao arquivo de sentimentos.

Pode-se considerar a escritura queer e o arquivo de sentimentos enquanto conceitos que abrangem um enquadramento mais amplo. Assim, enquanto o primeiro implica na singularidade histórica de uma obra, que amarra o(a) autor(a)/criador(a) e a sociedade em que vive, e o segundo a formação de uma memória compartilhada por pessoas com vivência de traumas em comum, é possível tomar esses conceitos como ferramentas de localização da obra na busca de compreender a 
emergência do fenômeno, em seu sentido genealógico. Tal como Colling (2016) e Giovanni (2015) fazem.

As noções de escrita transformista, língua/literatura menor e de focalização são complementares à escritura queer, porque identificam formas encarnadas dessa escritura. Assim, também seguindo a análise genealógica, elas funcionam como ferramentas de análise da proveniência, sendo essas compreendidas, conforme já foi explicado com base em Colling (2016), como as marcas no corpo imprimidas pela história.

Esse mapeamento da proveniência também é possível de ser feito com as categorias abordadas pelas pesquisadoras e pesquisadores nas outras formas de arte, como o cinema e a performance. A apropriação do conceito butleriano de performatividade, como fizeram Santos (2013) e Braga (2015), é bastante interessante e abre espaço para adaptações. O exercício realizado constrói categorias a partir das marcas culturais de gênero e como as obras analisadas se comportam em relação à heteronormatividade, entre assimilações e tensões.

Esse mesmo tipo de abertura está presente nas apropriações de Cysneiros (2014), com conceitos como família e fracasso. Inclusive, eles mesmos dialogam com o conceito de performatividade, já que o jeito como são mobilizados para a análise do autor são justamente em como a obra analisada se comportava diante da heteronormatividade, implicando em performatividades de gênero e sexualidade que rompem com a norma.

Assim, tem-se a seguinte esquematização:

Quadro 1: Sistematização de indicações metodológicas para se
analisar a arte por uma perspectiva queer 


\begin{tabular}{|c|c|c|}
\hline $\begin{array}{l}\text { Movimentos } \\
\text { metodológicos }\end{array}$ & $\begin{array}{l}\text { O que } \\
\text { fazer }\end{array}$ & $\begin{array}{l}\text { Conceitos } \mathrm{e} \\
\text { categorias úteis }\end{array}$ \\
\hline $\begin{array}{l}\text { Caracterização } \\
\text { da manifestação } \\
\text { artística }\end{array}$ & $\begin{array}{l}\text { Descrever } \\
\text { fenômeno } \\
\text { artístico }\end{array}$ & --------- \\
\hline Marcas artivistas & $\begin{array}{l}\text { Identificar } \\
\text { marcas que } \\
\text { podem } \\
\text { enquadrar essa } \\
\text { manifestação } \\
\text { como artivista }\end{array}$ & $\begin{array}{l}\text { Artivismo - revisar e } \\
\text { acompanhar os } \\
\text { debates sobre o } \\
\text { conceito, sempre } \\
\text { tensionando a relação } \\
\text { do alvo de interesse } \\
\text { de estudo com a } \\
\text { categoria. }\end{array}$ \\
\hline $\begin{array}{l}\text { Análise } \\
\text { genealógica }\end{array}$ & $\begin{array}{l}\text { Analisar } \\
\text { emergência e a } \\
\text { proveniência do } \\
\text { fenômeno }\end{array}$ & $\begin{array}{l}\text { Ferramentas de } \\
\text { localização } \\
\text { (emergência): } \\
\text { escritura de de } \\
\text { arquivo } \\
\text { sentimento } \\
\text { Ferramentas } \\
\text { análise } \\
\text { (proveniência): } \\
\text { performatividade em } \\
\text { relação com os } \\
\text { conceitos de família } \\
\text { e fracasso }\end{array}$ \\
\hline
\end{tabular}

Naturalmente, a proposta desse quadro não é ser uma camisa de força. Sua função é servir como sugestão de roteiro de pesquisa com 
indicações metodológicas de forma flexível e adaptável. É inegável que irá sofrer transformações ao longo da pesquisa, com a adição de novos conceitos e movimentos metodológicos. Algumas perguntas que surgem como norteadoras dessas análises e podem facilitar o estabelecimento dos objetivos de pesquisa são:

- Quais são as características dessa forma de arte?

- De que modo ela se relaciona com a política?

- Essa arte pode ser classificada como artivista? Por quê?

- Que metodologia, conceitos e categorias analíticas a especificidade da linguagem dessa arte demanda?

- Que conceitos dos estudos queer podem ser mobilizados nessa análise, seja para a reflexão teórica ou enquanto categoria de análise?

\section{Considerações finais}

Como foi possível ver por meio deste exercício de sistematização, já se tem um ponto de partida para se pensar a análise das artes a partir de uma perspectiva queer. Principalmente daquelas que se enquadram no que se tentou definir aqui como "artivismo" e em como algumas dessas manifestações artísticas se alinham às dissidências sexuais e de gênero.

Por meio da revisão e sistematização das principais operações metodológicas e dos conceitos e categorias de análises mobilizados por autoras(es) dos estudos queer para se pensar produções artísticas foi possível se esquematizar um quadro com indicações do caminho a ser percorrido. Como já foi dito, esse quadro é flexível e adaptável e será modificado conforme as pesquisas sobre o assunto avancem. Sua divisão em movimentos metodológicos, ações e conceitos/categorias objetiva sintetizar aspectos da pesquisa de modo que facilite sua composição.

Fica evidente, no entanto, o quanto falta para responder muitas das inquietações levantadas pelo fenômeno. A começar por um trabalho de revisão em profundidade de conhecimentos da área da arte e da estética. 
Apesar de alguns dos autores(as) aqui discutidos realizarem esse trabalho em suas pesquisas, ela é feita ainda visando atender somente as demandas pontuais daqueles estudos.

É necessário discutir de modo mais denso o conceito de "artivismo". Acredita-se que revisar a relação entre estética, arte e sociedade é um empreendimento que auxilie nessa discussão. Isso se faz ainda mais necessário quando há proliferação e maior visibilidade de artistas alinhados a uma perspectiva queer, a que se refere Colling (2016). Eles chamam atenção ao fato de que gênero e sexualidade sempre foram, também, uma questão estética. Essa constatação demanda reflexão quando se atenta para o contexto de apropriações dessas formas artísticas pelo mercado de consumo atual e para as potencialidades (positivas e negativas) geradas pela Internet e a hiperconectividade na produção e disseminação dessas produções e representações.

\section{Referências}

ALÓS, Anselmo. Gênero e ambivalência sexual na ficção de Caio Fernando Abreu: um olhar oblíquo sobre Onde andará Dulce Veiga? Estudos de literatura brasileira contemporânea, n. 40, jul./dez. 2012, p. 177-204.

AZEVEDO, Adriana P. F. de. Reconstruções Queers. Por uma utopia do lar. Tese (doutorado) - Pontifícia Universidade Católica do Rio de Janeiro. Rio de Janeiro, 2016, p. 144.

BLANCA, Rosa. Performance: entre el arte, la identidad, la vida y la muerte. Cadernos Pagu (46), jan.-abr., 2016, p. 439-460.

BRAGA, Cíntia. Desejos desviantes e imagem cinematográfica. Dissertação (Mestrado) - Instituto de Humanidades, Artes e Ciências Prof. Milton Santos, Programa Multidisciplinar de Pós-Graduação em Cultura e Sociedade, Universidade Federal da Bahia. Salvador, 2015, p. 149.

BUTLER, Judith. Problemas de gênero: feminismo e subversão da identidade. 5 ed. Rio de Janeiro: Civilização Brasileira, 2013.

COLLING, Leandro. A emergência do artivismo da dissidência sexual e de gênero no Brasil da atualidade. In: GARCÍA, Paulo César; 
THÜRLER, Djalma (Org.). Erotização da política e a política do desejo: narrativas de gênero e sexualidades em tempos de cólera. Salvador, EDUNEB, p. 74-86, 2016.

CVETKOVICH, Ann. An Archive of Feelings: Trauma, Sexuality and Lesbian Public Cultures. Durhan \& Londres: Duke University Press, 2003.

CYSNEIROS, Adriano. Da transgressão confinada às novas possibilidades de subjetivação: resgate e atualização do legado Dzi a partir do documentário Dzi Croquettes. Dissertação (Mestrado) Instituto de Humanidades, Artes e Ciências Prof. Milton Santos, Programa Multidisciplinar de Pós-Graduação em Cultura e Sociedade, Universidade Federal da Bahia. Salvador, 2014, p. 114.

DELEUZE, Gilles; GUATTARI, Félix. Kafka: por una literatura menor. México: Ediciones Era, 1978.

GIOVANNI, Julia Ruiz di. Artes de abrir espaço. Apontamentos para a análise de práticas em trânsito entre arte e ativismo. In.: Cadernos de Arte e Antropologia. Dossiê Artivismo: políticas e performances políticas na rua e na rede. Vol. 4, n. 2, 2015, p. 13-27.

HALBERSTAM, Judith Jack. Repensando o Sexo e o Gênero. In: MISKOLCI, Richard; PELÚCIO, Larissa (Org.). Discursos fora da ordem: sexualidades, saberes e direitos. São Paulo: Annablume; Fapesp, 2012.

HARAWAY, Donna. Saberes localizados: a questão da ciência para o feminismo e o privilégio da perspectiva parcial. Cadernos Pagú, (5):741, 1995.

MAIA, Helder T. C. O devir-darkoroom e a literatura hispanoamericana: a escritura queer de Néstor Perlongher e Copi. Dissertação (mestrado) - Universidade Federal Fluminense. Niterói, 2014, p. 161.

MOURÃO, Rui. Performances artivistas: incorporação duma estética de dissensão numa tica de resistência. Cadernos de Arte e Antropologia. Dossiê Artivismo: políticas e performances políticas na rua e na rede. Vol. 4, n. 2, 2015, 53-69.

RAPOSO, Paulo. "Artivismo": articulando dissidências, criando insurgências. Cadernos de Arte e Antropologia. Dossiê Artivismo: 
políticas e performances políticas na rua e na rede. Vol. 4, n. 2, 2015, 312.

ROLNIK, Suely. Cartografia Sentimental: transformações contemporâneas do desejo. Porto Alegre: Sulina; UFRGS Editora, 2006.

SANT'ANA, Tiago. Outras cenas do queer à brasileira: o grito gongadeiro de Jormard Muniz de Britto no cinema da Recinfernália. Dissertação (Mestrado) - Instituto de Humanidades, Artes e Ciências Prof. Milton Santos, Programa Multidisciplinar de PósGraduação em Cultura e Sociedade, Universidade Federal da Bahia. Salvador, 2016.

SANTOS, Matheus. Imagem-Abjeto: um estudo sobre manifestações estéticas da abjeção. Dissertação (mestrado) - Escola de Comunicação da Universidade Federal do Rio de Janeiro, Programa de Pós-Graduação em Comunicação e Cultura. Rio de Janeiro, 2013.

SLUZKI, Carlos E. Humilhação, Vergonha e Emoções Sociais Associadas: enfoque sistêmico e guia para sua transformação. In: BIGLIANI, Carlos Guillermo; MOGUILLANSKI, Rodolfo; SLUZKI, Carlos E.. Humilhação e Vergonha: um diálogo entre enfoques sistêmicos e psicanalíticos. São Paulo: Zagodoni, 2011, p. 71-106.

SONTAG, Susan. Notas sobre o camp. In: SONTAG, Susan. Contra a interpretação. Porto Alegre: L\&PM, 1987.

TEIXEIRA, Renata P. Copi: transgressão e escrita transformista. Tese (doutorado) - Universidade Federal de Pernambuco. Recife, 2007, p. 220 .

VIDAL-ORTIZ, Salvador; VITERI, Marva Amelia; AMAYA, José Fernando Serrano. Resignificaciones, practicas y políticas queer en América Latina: otra agenda de cambio social. Nomadas (Online), n. 41, pp. 185-201, 2014.

Recebido em 14/11/2016

Aprovado em 12/12/2016 